\title{
Successful sublingual immunotherapy for severe egg allergy in children: a case report
}

\author{
Nagatoshi Sagara, Satoshi Fujita, Ryohei Suzuki, Akiko Aota, Kenichi Akashi and Toshio Katsunuma* (i)
}

\begin{abstract}
Background: Egg allergy is one of the most common food allergies in children. To date, oral immunotherapy (OIT) has been considered as a promising treatment option for egg allergy. However, safety issues remain concerning severe adverse events requiring epinephrine injection. Hence, establishing a safer method to treat egg allergy would be beneficial. We report here two children with egg allergy who were safely treated with sublingual immunotherapy (SLIT) before transitioning to OIT.

Case presentation: Patient 1 was a 7-year-old girl and Patient 2 was a 5-year-old girl. Although OIT for egg had been attempted in both patients, severe anaphylactic symptoms were induced by ingesting only $0.1 \mathrm{~g}$ of heated whole egg. Therefore, SLIT was conducted with aqueous suspensions consisting of water and heated whole egg powder. Suspensions were administered sublingually, kept in the mouth for $2 \mathrm{~min}$, and spat out immediately thereafter. SLIT was continued for 7 months for Patient 1 and 8 months for Patient 2 due to the exploratory character of the study. Afterwards, the patients successfully transferred to low-dose OIT with $1 \mathrm{~g}$ of heated whole egg $(\fallingdotseq 170 \mathrm{mg}$ of egg protein) daily, and are continuing the therapy as of June 2020. As for adverse reactions, Patient 1 expressed oral cavity itchiness once at the beginning of SLIT. Patient 2 had no adverse reaction. The levels of antigen-specific lgE decreased in both patients after SLIT, and further decreased after switching to OIT.

Conclusions: Few clinical studies have evaluated the efficacy and safety of SLIT for egg allergy. Although the treatment was conducted in only two patients, our results have shown that SLIT is a promising treatment procedure for egg allergy. Further clinical trials will be needed to additionally assess the efficacy and safety of SLIT in children with food allergy.
\end{abstract}

Keywords: Case report, Egg, Food allergy, Pediatrics, Sublingual immunotherapy

\section{Background}

Egg allergy is one of the most common immunoglobulin $\mathrm{E}$ (IgE) mediated food allergies in children [1]. Although eliminating the causative food allergen from the child's diet is the current standard of care, this creates a tremendous burden on their families. In addition, complete adherence to egg-free diet is difficult because a variety of food contain hidden or difficult to recognize egg ingredients such as ovalbumin and ovomucoid. As a

*Correspondence: tkatsunuma@jikei.ac.jp

Department of Pediatrics, Daisan Hospital, The Jikei University School

of Medicine, 4-11-1, Izumihoncho, Komae-shi, Tokyo 201-8601, Japan result, children with egg allergy constantly have a risk of anaphylaxis resulting from accidental ingestion of eggcontaining foods.

Recently, oral immunotherapy (OIT) has been considered a promising treatment option for egg allergy. For example, a systematic review of 10 randomized controlled trials has shown that nearly half of children receiving OIT were able to tolerate a full serving of egg [2]. However, this approach has safety issues with $8.4 \%$ of patients receiving OIT having severe adverse reactions requiring epinephrine [2]. Hence, establishing a safer method to treat egg allergy is advisable. 
Sublingual immunotherapy (SLIT) is another treatment option, in which an allergen extract is held under the tongue for a short period of time. Mechanistically, SLIT may have some advantages by delivering the allergen to the antigen-presenting cells in oral mucosa. However, few clinical studies have evaluated its efficacy and safety. Recently, we treated two children with severe egg allergy with SLIT. Here, we report these cases.

\section{Case presentation}

Patient 1 was a 7-year-old girl with a history of Group B streptococcus meningitis before 1 year of age. Because she had atopic dermatitis, a blood test for antigenspecific IgE was performed at 10 months of age, resulting 90.7 UA/mL and $48.2 \mathrm{UA} / \mathrm{mL}$ for egg-white and ovomucoid respectively. Since then, egg and also peanut (which she also had an elevation of specific antibodies) had been eliminated from her diet. At 2 years of age, accidental consumption of egg white powder contained in a salad lead to eruption of urticaria and vomiting. When she was 3 years old, OFC was performed with a total consumption of $0.3 \mathrm{~g}$ of whole egg leading to cough symptoms. By the time of intervention with SLIT, she also had been diagnosed as asthma and allergic rhinitis complementing with egg allergy.

Patient 2 was a 5-year-old girl who had a history of anaphylaxis at 10 months of age when she took a small amount of boiled egg yolk. Furthermore, she had mild asthma and food allergy for salmon roe.

Although OIT for egg was attempted in both patients, anaphylactic symptoms were induced by ingesting only $0.1 \mathrm{~g}$ of heated whole egg as a single dose (vomiting, abdominal discomfort, urticaria for patient 1 and nausea, yawning, throat discomfort, decrease of blood pressure for patient 2). Because the patients and their parents were eager to receive treatment for egg allergy, we decided to attempt SLIT. The treatment was conducted after achieving an approval from the institutional review board of the Jikei University School of Medicine. Written informed consent was obtained from the parents.

SLIT was conducted in accordance with the following procedures. Aqueous suspensions were prepared by adding water to the heated whole egg powder (containing an equivalent of $0.69 \mathrm{~g}$ egg in $1.2 \mathrm{~mL}=120 \mathrm{mg}$ of egg protein). Each suspension was stored in a frozen state and thawed before usage. The solution was administered sublingually, kept in the mouth for $2 \mathrm{~min}$, and spat out immediately thereafter.

For Patient 1, the dose of SLIT was increased gradually from the starting dose of $0.04 \mathrm{~g}$ to $0.69 \mathrm{~g}$ under the hospitalized setting for 4 days (Table 1). For Patient 2, the starting dose was $0.04 \mathrm{~g}$, and the dose was increased to $0.08 \mathrm{~g}$ in the hospital on Day 1. Thereafter, SLIT was
Table 1 Dose titration schedule of sublingual immunotherapy

\begin{tabular}{llllll}
\hline \multicolumn{5}{l}{ Dose equivalent to the whole egg (g) } \\
\hline Patient 1 & & & & & \\
Day 1 & & & & & \\
Day 2 & 0.04 & 0.07 & 0.15 & 0.22 & \\
Day 3 & 0.11 & 0.17 & 0.23 & 0.34 & 0.46 \\
Day 4 & 0.34 & 0.46 & 0.57 & 0.69 & \\
After Day 5 & 0.69 & 0.69 & 0.69 & \\
Patient 2 & 0.69 & & & \\
Day 1 & & & & \\
Days 2 to 7 & 0.04 & 0.08 & & \\
Day 8 & 0.08 & & & \\
Days 9 to 35 & 0.16 & 0.24 & & \\
Day 36 & 0.24 & & & \\
Days 37 to 64 & 0.3 & 0.4 & \\
Day 65 & 0.4 & & \\
After Day 65 & 0.5 & 0.6 & \\
\hline
\end{tabular}

a Dose was increased at 2- or 3-h intervals in the hospital

conducted at home. The dose was increased again in the hospital on Days 8, 36, and 64 (Table 1). We instructed the parents of both patients to inject epinephrine (Epipen ${ }^{\circledR}$, Mylan N. V., Tokyo) in case anaphylactic symptoms were observed at home.

Once the dose reached $0.69 \mathrm{~g}$ for Patient 1 and $0.6 \mathrm{~g}$ for Patient 2, both patients continued daily maintenance SLIT at home. At first, SLIT was scheduled for 6 months. However, it was continued for 7 months for Patient 1 and 8 months for Patient 2 due to the exploratory character of the study. During the treatment, Patient 1 reported itchiness of the oral cavity just once when the dose was increased to $0.34 \mathrm{~g}$ on Day 2. No adverse reaction was observed in Patient 2. The level of antigen-specific IgE decreased in both patients after SLIT (Table 2).

Because the maximum liquid volume of the suspension which could be held in the sublingual space of children was considered to be $1.2 \mathrm{~mL}$, we could no further increase the dose of SLIT. In addition, the long-term efficacy of OIT had been recognized to be superior to that of SLIT [3]. As a result, SLIT was switched to OIT with low-dose heated whole egg, which was conducted by modifying the procedures previously reported [4]. After switching to OIT, the dose was gradually increased by $10 \%$ or $20 \%$ until achieving a maintenance dose of $1 \mathrm{~g}$ of heated whole egg ( $\fallingdotseq 170 \mathrm{mg}$ of egg protein) until June 2020. During OIT, no adverse reaction was observed in both patients, and the antigen-specific IgE levels decreased further (Table 2). Since we have not performed oral challenge tests after discontinuation of OIT, we cannot confirm whether the patients successfully achieved true tolerance 
Table 2 Changes in the antigen-specific immunoglobulin E levels

\begin{tabular}{lcc}
\hline & Patient 1 & Patient 2 \\
\hline Egg white specific $\operatorname{lgE}(\mathrm{UA} / \mathrm{mL})$ & & \\
Before starting SLIT & 56.1 & 14.4 \\
At the completion of SLIT & 42.8 & 9.65 \\
During OIT (at Mar/2020) & 18.7 & 6.29 \\
Ovomucoid specific lgE (UA/mL) & & \\
Before starting SLIT & 37.7 & 10.3 \\
At the completion of SLIT & 33.8 & 6.79 \\
During OIT (at Mar/2020) & 12.4 & 4.59 \\
\hline
\end{tabular}

IgE immunoglobulin E, SLIT Sublingual immunotherapy, and OIT oral immunotherapy

or not. However, the fact that these patients are able to take $1 \mathrm{~g}$ of heated whole egg safely every day, and the decrease of antigen-specific IgE levels indicates that these patients are now in the process of achieving tolerance. Thus, we are planning to continue OIT for these patients for the next several years.

\section{Discussion and conclusions}

Immunotherapy aims to induce immune tolerance by administering a confirmed allergen and can potentially be used as a curative treatment for food allergy [5]. However, OIT can induce serious adverse reactions such as anaphylaxis [6]. For this reason, OIT is not recommended as a standard treatment in most major treatment guidelines [7]. In contrast, SLIT is expected to minimize severe adverse reactions [8]. It may also have advantages by delivering the antigen to the antigenpresenting cells in an intact form before digestion in the stomach [9].

SLIT has been widely used as a method of treating allergic diseases induced by aeroallergens such as mite antigens or pollen antigens, [10] but few clinical studies have evaluated the efficacy and safety of SLIT for egg allergy. In our investigation, we were able to safely treat two children with SLIT followed by OIT. Initially, these children gave up OIT because of serious allergic reactions even at a low dose of $0.1 \mathrm{~g}$ of heated whole egg. Although the treatment was conducted in only two patients, our results suggest that SLIT may be a promising treatment approach for egg allergy. Finally, even though current standard therapeutic options for a motivated family/ patient who are unable to tolerate standard OIT would be a combination of omalizumab with typical OIT, [11] SLIT would be a much less expensive and less invasive option for such patients. Further clinical trials will be needed to additionally assess the efficacy and safety of SLIT in children with food allergy.

\section{Abbreviations}

IgE: Immunoglobulin E; SLIT: Sublingual immunotherapy; OIT: Oral immunotherapy.

\section{Acknowledgements}

Writing and editing assistance was provided by Kenichi Hayashi (Alamedic Co. Ltd) under contract with author TK.

\section{Authors' contributions}

TK, KA, AA, contributed to the design of the work and interpreted the data. NS, RS, SF contributed to the implementation and analysis of the study. TK and SF revised the manuscript. All authors contributed to the description of cases and to the final preparation of this manuscript. All authors read and approved the final manuscript.

\section{Funding}

No funding was provided for this research.

\section{Availability of data and materials}

All data generated or analyzed during this study are included in this published article.

\section{Ethics approval and consent to participate}

Ethics approval and consent to participate has been given by the patients, and the patients' parents. The study was approved by the Jikei University School of Medicine ethics committee: reference number 26-057(7562).

\section{Consent for publication}

Written informed consent was obtained from the patients' parents for publication of this case report.

\section{Competing interests}

The authors declare that they have no competing interests.

Received: 6 July 2020 Accepted: 15 December 2020

Published online: 06 January 2021

\section{References}

1. Savage J, Johns CB. Food allergy: epidemiology and natural history. Immunol Allergy Clin North Am. 2015;35:45-59.

2. Romantsik O, Tosca MA, Zappettini S, Calevo MG. Oral and sublingual immunotherapy for egg allergy. Cochrane Database of Syst Rev. 2018;20:4.

3. Narisety SD, Keet CA. Sublingual vs oral immunotherapy for food allergy: identifying the right approach. Drugs. 2012;72:1977-89.

4. Yanagida N, Sato S, Ebisawa M, et al. Safety and efficacy of low-dose oral immunotherapy for hen's egg allergy in children. Int Arch Allergy Immunol. 2016;171:265-8.

5. Longo G, Barbi E, Berti I, et al. Specific oral tolerance induction in children with very severe cow's milk-induced reactions. J Allergy Clin Immunol. 2008;121:343-7.

6. Varshney P, Steele PH, Vickery BP, et al. Adverse reactions during peanut oral immunotherapy home dosing. J Allergy Clin Immunol. 2009;124:1351-2.

7. Boyce JA, Assa'ad A, Burks AW, et al. Guidelines for the diagnosis and management of food allergy in the United States: summary of the NIAIDsponsored expert panel report. Nutr Res. 2011;31:61-75.

8. Passalacqua G, Bagnasco D, Canonica GW. 30 years of sublingual immunotherapy. Allergy. 2020:75:1107-20.

9. Scurlock AM. Oral and sublingual immunotherapy for treatment of IgEmediated food allergy. Clin Rev Allergy Immunol. 2018:55:139-52.

10. Demoly P, Passalacqua G, Calderon MA, Yalaoui T. Choosing the optimal dose in sublingual immunotherapy: rationale for the 300 index of reactivity dose. Clin Transl Allergy. 2015;5:44. 
11. Bégin P, Chan ES, Kim H, et al. CSACl guidelines for the ethical, evidencebased and patient-oriented clinical practice of oral immunotherapy in IgE-mediated food allergy. Allergy Asthma Clin Immunol. 2020;16:20.

\section{Publisher's Note}

Springer Nature remains neutral with regard to jurisdictional claims in published maps and institutional affiliations.
Ready to submit your research? Choose BMC and benefit from:

- fast, convenient online submission

- thorough peer review by experienced researchers in your field

- rapid publication on acceptance

- support for research data, including large and complex data types

- gold Open Access which fosters wider collaboration and increased citations

- maximum visibility for your research: over $100 \mathrm{M}$ website views per year

At BMC, research is always in progress.

Learn more biomedcentral.com/submissions 